Www.jmscr.igmpublication.org

Impact Factor (SJIF): 6.379

Index Copernicus Value: 71.58

ISSN (e)-2347-176x ISSN (p) 2455-0450

crossrefDOI: https://dx.doi.org/10.18535/jmscr/v6i7.183

Journal Of Medical Science And Clinical Research

\title{
Validation of Lrinec Score for Necrotising Fasciitis -Our Experience
}

\author{
Authors \\ Dr Narayanaswamy $\mathbf{T}^{1}$, Dr Athirath Reddy $K^{2}$
}

Kempegowda Institute of Medical Sciences and Research Centre K.R Road, VV Puram Bangalore

Pin: 560004, India

Corresponding Author

Dr Athirath Reddy K

Resident in Dept of Surgery, Kempegowda Institute of Medical Sciences and Research Centre K.R Road, VV Puram Bangalore Pin:560004, India

Email.athirathreddy@gmail.com,Ph:+919908877878

\begin{abstract}
Necrotizing fasciitis which is commonly known as "Flesh-Eating Disease" is a bacterial infection that spreads quickly and kills the body's soft-tissue. The paucity of specific cutaneous signs to distinguish necrotizing fasciitis from other soft tissue infections such as cellulitis makes the diagnosis extremely difficult. Modalities such as Computed tomography, Magnetic resonance imaging (MRI), and biopsy have been shown to be useful in the early recognition of necrotizing fasciitis, and routine application of these modalities in the evaluation of soft tissue infections has been limited by cost and availability. Laboratory Risk Indicator for Necrotizing Fasciitis (LRINEC) score or the LRINEC scoring system, devised by Wong et al ${ }^{36}$ in 2005 is an easy method and modality to follow and is also cost effective. Early diagnosis of necrotizing soft tissue infections is important for timely surgical intervention, but presenting physical exam findings can vary, so misdiagnosis is common ${ }^{(1)}$. Total of 100 subjects were studied by applying LRINEC score, who presented to KIMS Hospital, Bangalore with symptoms suggestive of soft tissue infections during the study period.
\end{abstract}

Keywords: LRINEC Scoring System, Necrotising Fasciitis (NF), C Reactive Protein, Poly Microbial Infections.

\section{Introduction}

Necrotizing fasciitis which is commonly known as "Flesh-Eating Disease" is a bacterial infection that spreads quickly and kills the body's softtissue. It is characterized by wide spread fascial necrosis with relative sparing of overlying skin and underlying muscle. Necrotizing soft tissue infections (NSTIs) are often encountered in surgical practice, especially in immunocompromised hosts ${ }^{2,3,4}$. Most often it is associated with severe systemic toxicity and a fulminant course. Usually it is rapidly fatal unless promptly recognized and aggressively treated with appropriate antimicrobials and surgical debridement at the earliest.

It is a rapidly progressive infection, primarily involving the fascia and subcutaneous tissue. Necrotizing soft tissue infection represents a diverse process; the term itself encompasses a continum ranging from pyoderma to life 
threatening infections. The common pyoderma does not extend beyond the skin (epidermis and dermis) and include erysipelas, impetigo, folliculitis, erythema, furunculosis and carbuncule. Cellulitis is a deeper skin infection than erysipelas. Necrotizing fasciitis involves the subcutaneous tissue, superficial fascia and deep fascia. These can occur in any anatomical areas but the common site is the extremities.

It has been shown by numerous studies in the past that early recognition and surgical intervention (Debridement) at early stage is the sole factor in preventing limb morbidity and mortality in patients with necrotizing fasciitis. The paucity of specific cutaneous signs to distinguish necrotizing fasciitis from other soft tissue infections such as cellulitis makes the diagnosis extremely difficult. Early clinical diagnosis of necrotizing fasciitis is difficult.

This necessitates for a simple and objective scoring system that helps in the diagnosis of the condition without much effort. One such scoring system is the Laboratory Risk Indicator for Necrotizing Fasciitis (LRINEC) score or the LRINEC scoring system, devised by Wong et al ${ }^{5}$ in 2005 which is easy to follow and cost effective, and is readily available at most centers. The LRINEC scoring system of Wong et a1 in 2005, is claimed to have a positive predictive value of $92.0 \%$ and negative predictive value of $96.0 \%$.

The Laboratory Risk Indicator for Necrotizing Fasciitis (LRINEC) was a retrospectively derived scoring tool designed to aid in the bedside diagnosis of necrotizing fasciitis. Published by Wong et al in 2004, it incorporated six routine laboratory tests (hemoglobin, creatinine, glucose, sodium, C-reactive protein, and white blood cell count) into a weighted 13 -point score ${ }^{5}$. Using a cut-off of $\geq 6$ points, the score was retrospectively validated in a small cohort, yielding a sensitivity of $90 \%$, specificity of $95 \%$, PPV of $92 \%$, and NPV of $96 \%$. These initial results were promising, but other retrospective studies of various sizes have been less optimistic, with LRINEC
Sensitivities of $48 \%-83 \%$ and Specificities of $60 \%-84 \%{ }^{6,7,8,9}$.

There are no prospective studies evaluating LRINEC performance. However, prospective American studies on NSTIs suggest that elevated WBC above 15.4 and hyponatremia below 135, components of the LRINEC, may have diagnostic value and can influence the decision to initiate surgical intervention ${ }^{10}$.

Hence, in this study, we have reviewed literature with regard to historical aspects, the epidemiology, aetiology, clinical presentation, diagnosis and treatment .If found to have similar comparable predictive values, this would help us diagnose and treat necrotizing fasciitis early and accurately in India where the mortality rates due to Necrotizing fasciitis is as high as $76 \%$.

With this background, a study was conducted among patients presenting with soft tissue infection to KIMS hospital, Bangalore in which, this scoring system was applied for early diagnosis of necrotizing fasciitis.

\section{Materials and Methods}

The study was conducted from December 2015 to July 2017 in the Department of Surgery of KIMS Hospital, Bengaluru. It is a Hospital Observational Study. Patients presenting with symptoms suggestive of soft tissue infections during the study period were included in the study

\section{Exclusion Criteria}

1. Patients below 15 years of age or above 75 years of age.

2. Patients who received antibiotic treatment in the preceding 48 hours or a minimum of 3 doses of antibiotic prior to presentation.

3. Patient who underwent surgical debridement for present episode of soft tissue infection.

4. Patients with infections with no evidence of cellulitis.

LRINEC scoring system will be applied to each of the study subjects. 
The confirmatory diagnosis for necrotising fasciitis will be done vide histopathology for all patients, pus and tissue for c/s and gram stain, irrespective of the result of the LRINEC scoring system.

Wong et al., 2005 have created a score, the LRINEC score wherein, they have compared a set of laboratory variables between patients with necrotizing and non-necrotizing soft tissue infections and identified 6 independent variables associated with NSTI.

The LRINEC (Laboratory Risk Indicator for Necrotizing Fasciitis) Score

$\begin{array}{lr}\text { Variable } & \text { Score } \\ \text { C-reactive Protein }(\mathrm{mg} / \mathrm{l}) & \\ \quad<150 & 0 \\ 150 \text { or more } & 4 \\ \text { Total White Cell Count }(\mathrm{mm} 3) & 0 \\ \quad<15 & 1 \\ 15-25 & 2 \\ \quad>25 & \\ \text { Haemoglobin }(\mathrm{g} / \mathrm{dl}) & 0 \\ >13.5 & 1 \\ 11-13.5 & 2 \\ <11 & \\ \text { Sodium }(\mathrm{mmol} / \mathrm{l}) & 0 \\ 135 \text { or more } & 2 \\ \quad<135 & \\ \text { Creatinine }(\mathrm{mg} / \mathrm{dl}) & 0 \\ 1.6 \text { or less } & \\ \quad>1.6 & 2 \\ \text { Glucose }(\mathrm{mg} / \mathrm{dl}) & \\ 180 \text { or less } & 0 \\ >180 & 1\end{array}$

LRINEC Score of 6 or greater is considered positive for Necrotizing Fasciitis.

\section{Results}

\section{Age Distribution}

Of the 100 patients included in the present study, seven age groups were formed, with their ages ranging from 15 years to 75 years, with a mean age group of $55.40 \pm 14.00$ years.

\begin{tabular}{|l|c|c|}
\hline Age in years & No. of patients & \% \\
\hline $\mathbf{1 5 - 2 0}$ & 2 & 2.0 \\
\hline $\mathbf{2 0 - 3 0}$ & 4 & 4.0 \\
\hline $\mathbf{3 1 - 4 0}$ & 13 & 13.0 \\
\hline $\mathbf{4 1 - 5 0}$ & 17 & 17.0 \\
\hline $\mathbf{5 1 - 6 0}$ & 20 & 20.0 \\
\hline $\mathbf{6 1 - 7 0}$ & 31 & 31.0 \\
\hline $\mathbf{7 1 - 7 5}$ & 13 & 13.0 \\
\hline Total & $\mathbf{1 0 0}$ & $\mathbf{1 0 0 . 0}$ \\
\hline
\end{tabular}

Sex Distribution: Out of the sample of 100, male are 76 and female are 24

\section{Gender distribution of patients studied}

\begin{tabular}{|l|c|c|}
\hline Gender & No. of patients & $\boldsymbol{\%}$ \\
\hline Female & 24 & 24.0 \\
\hline Male & 76 & 76.0 \\
\hline Total & $\mathbf{1 0 0}$ & $\mathbf{1 0 0 . 0}$ \\
\hline
\end{tabular}

CO Morbid Conditions: Out of 100 samples, 76 patients are presented with co-morbid conditions, whereas among 24 patients co-morbidity is not observed. The highest prevailing co-morbid condition is Diabetes Mellitus which is noticed among 67 patients.

\section{co- morbid distribution of patients studied}

\begin{tabular}{|c|c|c|}
\hline Co morbid & $\begin{array}{c}\text { No. of patients } \\
(\mathbf{n = 1 0 0})\end{array}$ & $\%$ \\
\hline Nil & 24 & $\mathbf{2 4 . 0}$ \\
\hline Yes & $\mathbf{7 6}$ & $\mathbf{7 6 . 0}$ \\
\hline$\bullet \quad$ DM & 67 & 67.0 \\
\hline$\bullet \quad$ PVD & 4 & 4.0 \\
\hline$\bullet \quad$ HTN & 3 & $\mathbf{3 . 0}$ \\
\hline$\bullet \quad$ Steroid Use & 2 & $\mathbf{2 . 0}$ \\
\hline
\end{tabular}

Signs and Symptoms: The common symptoms that prevailed in all 100 patients are 'Pain'\& 'Swelling'. The symptom 'Gangrene' was noticed in only 21 patients.

Signs and symptoms distribution of patients studied

\begin{tabular}{|l|c|c|}
\hline & $\begin{array}{c}\text { No. of patients } \\
(\mathbf{n}=\mathbf{1 0 0})\end{array}$ & $\mathbf{\%}$ \\
\hline Pain & 100 & 100.0 \\
\hline Discharge & 92 & 92.0 \\
\hline Swelling & 100 & 100.0 \\
\hline Necrosis & 47 & 47.0 \\
\hline Crepitus & 34 & 34.0 \\
\hline Gangrene & 21 & 21.0 \\
\hline Blebs & $\mathbf{9 0}$ & $\mathbf{9 0 . 0}$ \\
\hline
\end{tabular}

C-Reactive Protein: The C-Reactive Protein distribution is showing that $69 \%$ of sample are presented within the range of 15-30, the least being $8 \%$ under $>30$ with a Mean of $19.99 \pm 6.89$.

C - reactive protein distribution of patients studied

\begin{tabular}{|l|c|c|}
\hline C-Reactive Protein & No. of patients & $\boldsymbol{\%}$ \\
\hline$<\mathbf{1 5}$ & 23 & 23.0 \\
\hline $\mathbf{1 5 - 3 0}$ & 69 & 69.0 \\
\hline$>\mathbf{3 0}$ & 8 & 8.0 \\
\hline Total & $\mathbf{1 0 0}$ & $\mathbf{1 0 0 . 0}$ \\
\hline
\end{tabular}


hemoglobin (g/dl) distribution of patients studied

\begin{tabular}{|l|c|c|}
\hline Hemoglobin $(\mathbf{g} / \mathbf{d l})$ & No. of patients & $\mathbf{\%}$ \\
\hline$<\mathbf{1 2}$ & 60 & 60.0 \\
\hline $\mathbf{1 2 - 1 6}$ & 38 & 38.0 \\
\hline$>\mathbf{1 6}$ & 2 & 2.0 \\
\hline Total & $\mathbf{1 0 0}$ & $\mathbf{1 0 0 . 0}$ \\
\hline
\end{tabular}

Total Count: $85 \%$ of the sample are with $>11000$ Total Count and no patient is noticed as having $<4000$ with a Mean of $18251.58 \pm 7801.17$.

Total count (cells/cumm) distribution of patients studied

\begin{tabular}{|l|c|c|}
\hline Total Count (cells/cumm) & No. of patients & \% \\
\hline$<4000$ & 0 & 0.0 \\
\hline $\mathbf{4 0 0 0 - 1 1 0 0 0}$ & 15 & 15.0 \\
\hline$>\mathbf{1 1 0 0 0}$ & 85 & 85.0 \\
\hline Total & $\mathbf{1 0 0}$ & $\mathbf{1 0 0 . 0}$ \\
\hline
\end{tabular}

Serum Sodium: $67 \%$ of the sample are noticed having $<135$ of Sodium and no patient is reported with >146 Sodium level with a Mean of $129.31 \pm 13.22$.

sodium $(\mathrm{mEq} / \mathrm{l})$ distribution of patients studied:

\begin{tabular}{|l|c|c|}
\hline Sodium $(\mathbf{m E q} / \mathbf{l})$ & No. of patients & \% \\
\hline$<\mathbf{1 3 5}$ & 67 & 67.0 \\
\hline $\mathbf{1 3 5 - 1 4 6}$ & 33 & 33.0 \\
\hline$>\mathbf{1 4 6}$ & 0 & 0.0 \\
\hline Total & $\mathbf{1 0 0}$ & $\mathbf{1 0 0 . 0}$ \\
\hline
\end{tabular}

Serum Creatinine: $61 \%$ of the sample have shown the Serum Creatinine levels as $>1.1$ and $39 \%$ have shown it as $<1.1$ with a Mean of $1.39 \pm 0.78$.

Serum creatinine $(\mathrm{mg} / \mathrm{dl})$ distribution of patients studied

\begin{tabular}{|l|l|l|}
\hline Serum Creatinine (mg/dl) & No. of patients & \% \\
\hline$<\mathbf{1 . 1}$ & 39 & 39.0 \\
\hline$>\mathbf{1 . 1}$ & 61 & 61.0 \\
\hline Total & $\mathbf{1 0 0}$ & $\mathbf{1 0 0 . 0}$ \\
\hline
\end{tabular}

Blood Glucose: Much variation is not observed relating to Blood Glucose levels with $41 \%$ falling under $120-200,32 \%$ falling under $<120$ and $27 \%$

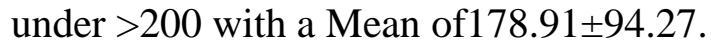

Glucose levels distribution of patients studied

\begin{tabular}{|l|c|c|}
\hline Glucose & No. of patients & \% \\
\hline$<\mathbf{1 2 0}$ & 32 & 32.0 \\
\hline $\mathbf{1 2 0 - 2 0 0}$ & 41 & 41.0 \\
\hline$>\mathbf{2 0 0}$ & 27 & 27.0 \\
\hline Total & $\mathbf{1 0 0}$ & $\mathbf{1 0 0 . 0}$ \\
\hline
\end{tabular}

Lrinec Score: $32 \%$ of sample are observed of having Total Score $<6$ with a least $3 \%$ of sample showing >12 Total Score and more patients i.e.65\% have shown possessing the Total Score as 6-12 with a Mean of 7.29 \pm 3.17 .

\section{Total score distribution of patients studied}

\begin{tabular}{|l|l|l|}
\hline Total Score & No. of patients & $\%$ \\
\hline$<6$ & 32 & 32.0 \\
\hline $6-12$ & 65 & 65.0 \\
\hline$>12$ & 3 & 3.0 \\
\hline Total & 100 & 100.0 \\
\hline
\end{tabular}

Surgical Intervention: The surgical interventions used for treatment of the patients are Debridement, Fasciotomy and Amputation, the procedure debridement conducted on among highest number of patients i.e. 59 followed by fasciotomy for 24 and amputation for 17 patients.

Treatment distribution of patients studied

\begin{tabular}{|l|c|c|}
\hline Treatment & No. of patients & $\%$ \\
\hline Debridement & 59 & 59.0 \\
\hline Fasciotomy & 24 & 24.0 \\
\hline Amputation & 17 & 17.0 \\
\hline Total & 100 & 100.0 \\
\hline
\end{tabular}

Culture (Organism - Bacteria): The sample showed that Klebsiella, Pseudomonas and Staphylococcus are the causative organisms for $50 \%$ of the sample and. $5 \%$ of the sample have not showed growth of any organism and $28 \%$ of the sample had Polymicrobial cause (infection).

Culture report of patients studied

\begin{tabular}{|l|c|c|}
\hline & $\begin{array}{c}\text { No. of patients } \\
(\mathbf{n = 1 0 0})\end{array}$ & $\%$ \\
\hline Polymicrobial & $\mathbf{2 8}$ & $\mathbf{2 8 . 0}$ \\
\hline Klebsiella & $\mathbf{1 8}$ & $\mathbf{1 8 . 0}$ \\
\hline Pseudomonas & 17 & 17.0 \\
\hline Staphylococcus & 15 & 15.0 \\
\hline Proteus & 9 & 9.0 \\
\hline E.coli & $\mathbf{8}$ & $\mathbf{8 . 0}$ \\
\hline No growth & 5 & $\mathbf{5 . 0}$ \\
\hline
\end{tabular}

Histopathological Report: $65 \%$ of the sample showed NF on Histopathological Examination and $35 \%$ are found negative for NF. 
Histopathological Examination Report

\begin{tabular}{|l|c|c|}
\hline $\begin{array}{l}\text { Histopathological } \\
\text { Examination Report }\end{array}$ & No. of patients & $\boldsymbol{\%}$ \\
\hline No NF & 35 & 35.0 \\
\hline NF & 65 & 65.0 \\
\hline Total & $\mathbf{1 0 0}$ & $\mathbf{1 0 0 . 0}$ \\
\hline
\end{tabular}

Statistical analysis of patients studied: Chisquare test

\begin{tabular}{|l|c|c|}
\hline Remarks & No. of patients & $\%$ \\
\hline Total Positive & $\mathbf{6 2}$ & $\mathbf{6 2 . 0}$ \\
\hline Total Negative & $\mathbf{3 0}$ & $\mathbf{3 0 . 0}$ \\
\hline False Positive & $\mathbf{6}$ & $\mathbf{6 . 0}$ \\
\hline False Negative & $\mathbf{2}$ & $\mathbf{2 . 0}$ \\
\hline Total & $\mathbf{1 0 0}$ & $\mathbf{1 0 0 . 0}$ \\
\hline
\end{tabular}

Correlation of Total Score with Histopathological Findings

\begin{tabular}{|l|c|c|c|c|}
\hline Remarks & $\begin{array}{c}\text { No. of } \\
\text { patients }\end{array}$ & $\%$ & $\begin{array}{c}\text { Diagnostic } \\
\text { value }\end{array}$ & $\%$ \\
\hline Total Positive & 62 & 62 & Sensitivity & 96.8 \\
\hline Total Negative & 30 & 30 & Specificity & 83.33 \\
\hline False Positive & 6 & 6 & PPV & 91.18 \\
\hline False Negative & 2 & 2 & NPV & 93.75 \\
\hline Total & 100 & 100 & Accuracy & 92 \\
\hline
\end{tabular}

\section{Discussion}

Wong's study, 2003 was on the clinical presentation, microbiology, and determinants of mortality in Necrotizing fasciitis, in which the medical records of eighty-nine consecutive patients who had been admitted for necrotizing fasciitis were reviewed retrospectively, and it showed that only thirteen of the eighty-nine patients had a diagnosis of necrotizing fasciitis at the time of admission. Pre admission treatment with antibiotics modified the initial clinical picture and often masked the severity of the underlying infection. Polymicrobial synergistic infection was the most common cause (forty-eight patients; $53.9 \%$ ), with streptococci and enterobacteriaceae being the most common isolates. Group-A streptococcus was the most common cause of mono-microbial necrotizing fasciitis. The most common associated co-morbidity was diabetes mellitus (sixty-three patients; 70.8\%). Advanced age, two or more associated co morbidities, and a delay in surgery of more than twenty-four hours adversely affected the outcome, and only a delay in surgery of more than twenty-four hours was correlated with increased mortality $(\mathrm{p}<0.05)$ as shown by multivariate analysis.

Necrotizing fasciitis is a spreading facial gangrene that destroys the fascia with relative sparing of skin and muscle

In the present study, a total of 100 patients presenting with soft tissue infections were recruited into the study based on the inclusion and exclusion criteria mentioned earlier. Most common age group was between $61-70$ years, and $2^{\text {nd }}$ most common age group was between $61-70$ years. Mean age group was : $55.40 \pm 14.00$ years The majority of the patients belonged to male category with a $76 \%$ and female $24 \%$ respectively. This indicates that the incidence of NF is higher in males than females. Anaya, D.A, et al (2005) has reported that NF commonly occurs in male with a ratio between male and female as 3:1, more frequently effecting the extremities. This can be attributed to the increased prevalence of practices like smoking, and diabetes among males compared to females.

The results indicate that patients with co morbidity are higher and the most frequent co morbidity being Diabetes mellitus (67\%). Nissar Shaikh, $2006^{11}$ has found that $53 \%$ of patients were diabetic and Chung, J.P.Y et al, 2009 reported that $57 \%$ patients of his study had Diabetes mellitus.

It was found that the common symptoms observed in all the 100 patients was pain and swelling followed by the discharge (92\%) and Blebs (90). Gangrene was found in only $21 \%$ patients. Mc Henry et al, 1995 reported that initial signs and symptoms include pain, swelling and erythema. As the infection gets progressed, edema occur outside the area of compromised skin, disproportionate pain, discolouration of the skin, blisters, bullae and crepitus.

$77 \%$ patients were having C-reactive protein levels more than and equal to $150 \mathrm{mg} / \mathrm{L}$, which can be due to presence of tissue damage 
The PPV and NPV of our study are $91.18 \%$ and $96 \%$ respectively and when compared with Wong et al study it was found to have comparable values.

\begin{tabular}{|l|c|c|c|c|}
\hline & Sensitivity & Specificity & PPV & NPV \\
\hline Wong & $89.9 \%$ & $96.9 \%$ & $92 \%$ & $96 \%$ \\
\hline $\begin{array}{l}\text { Our } \\
\text { study }\end{array}$ & $96.8 \%$ & $83.33 \%$ & $91.18 \%$ & $93.75 \%$ \\
\hline
\end{tabular}

$\mathrm{P}<0.001^{* *}$, Significant, Chi-Square test

LRINEC score has an impressive ability to predict need for early surgical intervention in NF.We found that in our study there was fairly high false positive rate; hence application of LRINEC score alone has tendency to over treat patient with NF

\section{References}

1. Goh T, Goh LG, Ang CH, Wong $\mathrm{CH}$. Early diagnosis of necrotizing fasciitis. Br J Surg. 2014;101(1):e119e125. doi:10.1002/bjs.9371.

2. Anaya DA, Dellinger EP. Necrotizing softtissue infection: Diagnosis and management. Clin Infect Dis.2007;44: 705-10. [PubMed]

3. Elliot DC, Kufera JA, Myers RA. Necrotizing soft tissue infections. Risk factors for mortality and strategies for management. Ann Surg1996; 224(5):67283.

4. Mathews MS, Raman A, Nair A. Nosocomial zygomycotic post-surgical necrotizing fasciitis in a healthy adult caused by Apophysomyceselegans in south India. J Med Vet Mycol. 1997;35:613. [PubMed]

5. Wvoski MG, Santora TA. Necrotizing fascitis: CT characteristics. Radiology. 1997;203:859-863.[PubMed]

6. Schmid M R, Kossmann T, DueweII S. Differentiation of Necrotizing Fasciitis and Cellulitis Using MR Imaging. AJR. Mar 1998; 170: 615-620.

7. Chao W-N, Tsai S-J, Tsai C-F, et al. The Laboratory Risk Indicator for Necrotizing Fasciitis score for discernment of necrotizing fasciitis originated from Vibrio vulnificus infections. J Trauma Acute Care Surg. 2012;73(6):1576-1582.

8. Descamps V, Aitken J, Lee MG. Hippocrates on necrotizing fasciitis. Lancet 1994; 344:556.

9. Bernal NP, Latenser BA, Born JM, Liao J. Trends in 393 necrotizing acute soft tissue infection patients 2000-2008. Burns. 2012;38(2):252-260.

10. Swain RA, Hatcher JC, Azadian BS, Soni N, De Souza B. A five-year review of necrotising fasciitis in a tertiary referral unit. Ann R CollSurg Engl. 2013;95(1):5760. Townsend: Sabiston Textbook of Surgery, 18th Ed.p-2011.

11. Chan T, Yaghoubian A, Rosing D, Kaji A, de Virgilio C. Low sensitivity of physical examination findings in necrotizing soft tissue infection is improved with laboratory values: a prospective study. Am J Surg. 2008;196(6):926-930; discussion 930.

12. Nissar Shaiks, A Decade of Surgical Intensive Care Experience, Indian Journal of Critical Care \& Medicine, 2006, Vol:10, Issue:4, Pages:225-229. 